\title{
Alteration in basal and depolarization induced transcriptional network in iPSC derived neurons from Timothy syndrome
}

Yuan Tian ${ }^{1,2}$, Irina Voineagu ${ }^{3}$, Sergiu P Paşca ${ }^{4}$, Hyejung Won ${ }^{1}$, Vijayendran Chandran ${ }^{1}$, Steve Horvath ${ }^{5}$, Ricardo E Dolmetsch ${ }^{6,7}$ and Daniel $H$ Geschwind ${ }^{1,2,5^{*}}$

\begin{abstract}
Background: Common genetic variation and rare mutations in genes encoding calcium channel subunits have pleiotropic effects on risk for multiple neuropsychiatric disorders, including autism spectrum disorder (ASD) and schizophrenia. To gain further mechanistic insights by extending previous gene expression data, we constructed co-expression networks in Timothy syndrome (TS), a monogenic condition with high penetrance for ASD, caused by mutations in the L-type calcium channel, $\mathrm{Ca}_{\mathrm{v}} 1.2$.

Methods: To identify patient-specific alterations in transcriptome organization, we conducted a genome-wide weighted co-expression network analysis (WGCNA) on neural progenitors and neurons from multiple lines of induced pluripotent stem cells (iPSC) derived from normal and TS (G406R in CACNA1C) individuals. We employed transcription factor binding site enrichment analysis to assess whether TS associated co-expression changes reflect calcium-dependent co-regulation.

Results: We identified reproducible developmental and activity-dependent gene co-expression modules conserved in patient and control cell lines. By comparing cell lines from case and control subjects, we also identified co-expression modules reflecting distinct aspects of TS, including intellectual disability and ASD-related phenotypes. Moreover, by integrating co-expression with transcription factor binding analysis, we showed the TS-associated transcriptional changes were predicted to be co-regulated by calcium-dependent transcriptional regulators, including NFAT, MEF2, CREB, and FOXO, thus providing a mechanism by which altered $\mathrm{Ca}^{2+}$ signaling in TS patients leads to the observed molecular dysregulation.

Conclusions: We applied WGCNA to construct co-expression networks related to neural development and depolarization in IPSC-derived neural cells from TS and control individuals for the first time. These analyses illustrate how a systems biology approach based on gene networks can yield insights into the molecular mechanisms of neural development and function, and provide clues as to the functional impact of the downstream effects of $\mathrm{Ca}^{2+}$ signaling dysregulation on transcription.
\end{abstract}

\footnotetext{
* Correspondence: dhg@mednet.ucla.edu

${ }^{1}$ Neurogenetics Program, Department of Neurology, Center for Autism

Research and Treatment, Semel Institute, David Geffen School of Medicine,

University of California, Los Angeles, CA 90095, USA

${ }^{2}$ Interdepartmental Ph.D. Program in Bioinformatics, University of California,

Los Angeles, CA 90095, USA

Full list of author information is available at the end of the article
}

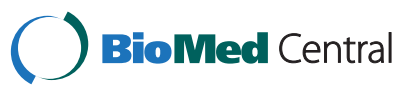

(c) 2014 Tian et al.; licensee BioMed Central Ltd. This is an Open Access article distributed under the terms of the Creative Commons Attribution License (http://creativecommons.org/licenses/by/4.0), which permits unrestricted use, distribution, and reproduction in any medium, provided the original work is properly credited. The Creative Commons Public Domain Dedication waiver (http://creativecommons.org/publicdomain/zero/1.0/) applies to the data made available in this article, unless otherwise stated. 


\section{Background}

The L-type calcium channel, $\mathrm{Ca}_{\mathrm{v}} 1.2$, plays a central role in regulating an activity-dependent signaling network that is essential for neuronal function [1-6]. A particularly salient example of a perturbation in $\mathrm{Ca}_{\mathrm{v}} 1.2$ function is Timothy syndrome (TS), a rare genetic disorder caused by dominant mutations in the gene $C A C N A 1 C$, which encodes the $\alpha$ subunit of the voltage-gated calcium channel $\mathrm{Ca}_{\mathrm{v}} 1.2$. TS mutations in this subunit result in a conformational change of $\mathrm{Ca}_{\mathrm{v}} 1.2$, leading to delayed channel inactivation and elevation of intracellular calcium upon depolarization [7-9]. TS patients typically exhibit a spectrum of severe nervous system abnormalities, including autism spectrum disorder (ASD) in up to $80 \%$ of the patients [8-10]. Given the increasing appreciation for rare monogenic contributions to ASD [11-13], TS provides a powerful avenue for understanding both basic neurobiological processes and ASD pathophysiology.

Given the pleiotropic manifestation of CACNA1C mutations in TS and the recent implication of common variation in CACNA1C across multiple neuropsychiatric disorders [14], we reasoned that characterization of the $\mathrm{Ca}_{\mathrm{v}}$ 1.2-dependent signaling network in TS would help elucidate its molecular basis and prioritize genes for therapeutic development. Although it has been known that calcium influx triggers massive transcriptional changes by acting through several transcription factors, including calcium response factor (CaRF) [15,16], myocyte enhancer factor-2 (MEF2) [17,18], nuclear factor of activated T-cells (NFAT) $[19,20]$, and cAMP response element-binding proteins (CREB) [21-24], little is known about their downstream targets in human neurons and how these processes are altered in disease states such as TS. Here, we reasoned that identifying alterations in mRNA transcript levels in TS patient-derived cortical progenitors and developing neurons would help clarify, not only how calcium regulates gene expression in TS, but more broadly inform our understanding of the molecular mechanism of ASD.

Previously, we reported that the TS mutation was associated with abnormalities in cortical neurogenesis, activitydependent dendrite retraction, and an excess production of catecholamines [25,26]. Here, to provide a higher order view of the transcriptional changes caused by the TS mutation in CACNA1C, we constructed genome-wide transcriptome networks in control and TS neural progenitors and differentiated neurons at rest and following depolarization. Using Weighted Gene Co-expression Network Analysis (WGCNA) [27,28], we identified gene co-expression modules associated with neural development, as well as depolarization shared across both patient and control lines. By comparing TS and control networks, we identified distinct TS related modules enriched in intellectual disability (ID) genes and ASD susceptibility genes. By further integrating the co-expression network with transcription factor binding analysis, we identified candidate regulators for disease-associated modules, including NFAT [19,20], MEF2 $[17,18]$, CREB [21-24], and forkhead box proteins $\mathrm{O}$ (FOXO) [29-32]. Our results provide a functional genomic framework for a calcium-dependent signaling network by highlighting the downstream transcriptional targets of $\mathrm{Ca}_{\mathrm{v}} 1.2$ dysregulation, and yields insights into molecular mechanisms relevant to both TS and ASD.

\section{Methods}

\section{Expression data set}

Expression data were obtained from Paşca et al. [25] (GSE25542). As previously described, cortical neural progenitors and neurons were generated from independent differentiation of four control iPSC lines from two normal subjects, three TS iPSC lines from one TS patient, and one human embryonic stem cell line (H9). All three subjects included in this expression projects are females. To obtain activity-dependent gene co-expression networks, neurons were treated with $67 \mathrm{mM} \mathrm{KCl}$ or vehicle, and harvested after $9 \mathrm{~h}$. The maturation of the specific neuronal cultures has been assessed with Fluidigm Dynamic Arrays and functional characterizations, including patch-clamp recording and live calcium imaging [25]. The analysis showed that at day 42 of differentiation in vitro most of the cells were electrically active, and expressed neuronal markers [25]. Moreover, most of the cells are lower layer cortical neurons, and around $20 \%$ are upper layer cortical neurons [25]. In terms of electrophysiological features, there are no significant differences between the TS cells and controls cells with regard to their action potential threshold or amplitude, resting membrane potential, input resistance or capacitance [25]. However, by time-lapse video microscopy assay with calcium indicator Fura-2, Paşca et al. showed electrophysiological abnormalities in these patient cells compared to controls, including abnormal calcium currents after depolarization and longer action potentials [25].

Total RNA was extracted using the RNeasy Mini kit (QIAGEN). cDNA labeling and hybridization on Illumina HumanRef-8 v3 Expression BeadChips (Illumina) were performed according to the manufacturer's protocol. Microarray data were analyzed with custom $\mathrm{R}$ scripts calling Bioconductor packages. Outlier arrays were detected based on low inter-sample correlations. Raw expression data were $\log _{2}$ transformed, and quantile normalized. Probes were considered robustly expressed if the detection $P$ value was $<0.05$ for at least half of the samples in the data set. Consequently, a total of 13,255 expressed genes from 12 neural progenitor cell lines, 15 neuronal cell lines at rest, and nine $\mathrm{KCl}$-depolarized neurons from cases and controls were used for network analysis.

Reproducibility is often an issue in iPSC studies. Here, although we only have one TS patient, two controls, and 
an additional control H9 ES cell line, we have five neuronal lines from the TS patient, and multiple lines for each control, both at rest and with $\mathrm{K}^{+}$induced depolarization. Within each cell type, cell lines derived from the same subject clustered more closely together than to the cell lines from different subjects. Particularly, the five TS neuronal lines all tightly clustered together. The average intrasubject variance between lines is low: 0.042, 0.053, 0.058, and 0.066 for the TS patient, $\mathrm{H} 9$, and the two controls, respectively. Additionally, the experimental data from Paşca et al. showed that these lines generated reliable and reproducible cell types at the genome-wide level [25].

\section{Weighted Gene Co-expression Network Analysis (WGCNA)}

We conducted signed co-expression network analysis using the R WGCNA package [27] as previously described [33-35]. WGCNA is based on topological overlap measurements derived from pairwise correlation-based adjacency values to estimate the neighborhood similarity among genes, followed by hierarchical clustering to identify gene co-expression modules. Instead of focusing on individual genes, WGCNA is highly effective for characterizing the features of co-expressed gene modules [36], each of which is represented by a color classifier. Here, the correlation values were raised by a power of 12 to satisfy scale-free criteria [27]. The minimum module size was set to 40 genes and the height for merging modules was set to 0.25 , which required at least $25 \%$ dissimilarity among modules in expression. We identified a total of 18 modules (Additional file 1: Table S1), each summarized by its eigengene (ME, defined as the first principal component of the standardized expression values [37]). The significance of module eigengene-phenotype association (cell type, mutation status, and resting vs. depolarization) was evaluated by a linear regression model using the $\mathrm{R} \mathrm{lm}$ function. Associations with FDR (Benjamini-Hochberg (BH) correction [38]) less than 0.05 was considered as significant. Genes were prioritized based on their correlation with the module eigengene (kME) [37]. The top connected genes (either kME $>0.6$ or the top 200, depending on which was smaller to facilitate visualization) were used to generate the module network plots via the $\mathrm{R}$ igraph package [39].

\section{Module preservation analysis}

Module preservation analysis was performed to investigate if density and connectivity based network measures were preserved across data sets and conditions [40]. A Zsummary statistic was computed to aggregate various preservation measures, and a threshold of 2 based on 200 permutations was used to determine significantly preserved modules.

We first assessed the preservation of modules identified in combined case and control samples in two independent data sets: (1) expression profiles of differentiating primary human neural progenitor cells in vitro over 12 weeks (phNPCs) (GSE57595) [41], and (2) expression data from developing human cortex (post conception week 4 through 6 months after birth) from Kang et al. (GSE25219) [41,42].

\section{Differential expression}

Differentiation-induced expression changes were assessed for cases and controls separately using the linear models in the R limma package [43]. The neural progenitors and neurons were paired if they were differentiated from the same iPSC clone and plated for differentiation in one experiment. The interaction effect was further evaluated using factorial designs implemented in limma. To be identified as showing dynamic expression changes upon differentiation in TS versus controls two criteria needed to be satisfied: (1) significant differential expression upon differentiation in either controls or TS, but not both; (2) a significant interaction effect between cell type (neural progenitor and neurons) and TS mutation status. The significance threshold was set at $P<0.05$ unless otherwise specified.

\section{Functional enrichment analysis}

Functional enrichment analysis was assessed using GOElite Pathway Analysis [44]. Two enrichment analyses were performed on the genes of interest by assessing: (1) enriched Gene Ontology (GO) categories, and (2) enriched KEGG pathways. GO-Elite performs permutations to obtain over-representation $\mathrm{Z}$ scores and enrichment $P$ values for each GO term. In our analysis, we performed 10,000 permutations to evaluate enrichment significance. The background was set to the total list of genes expressed in this data set. GO categories with a permuted $P<0.05$ were reported.

\section{Gene set over-representation analysis}

A one-sided Fisher exact test was performed to assess over-representation of module genes in other gene sets using the $\mathrm{R}$ function fisher.test. Depolarization-associated gene lists were curated from two publications (McKee et al. [45] and Kim et al. [46]). The ASD susceptibility genes were curated from the SFARI gene database [47]. Genes categorized as Syndromic (S) and those with associated scores in the range of 1 to 4 were used in our analysis. The ASDassociated co-expression modules asdM12 and asdM16 were obtained from Voineagu et al. [33]. The ID-associated genes were curated from four reviews [48-51] resulting in 401 genes as reported in Parikshak et al. [34].

\section{Transcription factor binding site (TFBS) enrichment analysis}

TFBS enrichment analysis was conducted by scanning the promoter sequence of the genes in the analyzed modules for enrichment of known transcription factor 
binding motifs using the Clover algorithm [52]. For every gene, we considered 1,000 bp upstream of its transcription start site as the candidate promoter region. The putative binding motifs were obtained from TRANSFAC $[53,54]$ in the format of position weight matrix. To comprehensively evaluate the statistical significance of the enrichment results, we utilized three different background datasets: 1,000 bp sequences upstream of all human genes, human $\mathrm{CpG}$ islands and the sequences of human chromosome 20 . We calculated the enrichment $P$ values from the null distribution generated by repeatedly drawing 1,000 random sequences of the same length from the background sequences. Significant events were defined at $P<0.05$ across all three backgrounds.

To confirm the validity of the predicted motif enrichment, we determined if existing chromatin immunoprecipitation (ChIP) data for transcription factors supported the predicted binding sites. The ChIP data sets were obtained from ENCODE [55,56] and ChIP Enrichment Analysis resource (ChEA) [57]. We reported the number of predicted binding targets that could be verified by corresponding transcription factor ChIP data from any tissues or cell lines where available. Statistical significance was evaluated by assessing the cumulative hypergeometric probability using phyper function in $\mathrm{R}$. The population size was defined as the total number of genes expressed in this data set.

\section{Results}

\section{Network construction and module detection}

To elucidate the transcriptional changes relevant to TS mutation at key stages, we constructed a co-expression network based on the expression profiles of cortical neural progenitor cells $(N=12)$ and differentiated cortical neurons, both at rest $(N=15)$ and after $\mathrm{KCl}$-induced depolarization $(N=9)$ (Figure $1 \mathrm{~A})$. As previously shown, iPSC lines were validated and the stages of neural differentiation in vitro were carefully characterized using a variety of immunocytochemical, physiological, and molecular assays, including Fluidigm Dynamic Arrays, patch-clamp recording, and live calcium imaging, to demonstrate the derived neurons expressed the appropriate molecular markers, were electrically active and fired action potentials [25] (Methods). Using a signed network analysis [27], we identified a total of 18 gene co-expression modules which were comprised of genes sharing highly similar expression patterns across samples. As shown in Figure 1B, genes that clustered into modules based upon co-expression also shared functional annotations, indicating that they participate in common biological processes.

We next assessed the reproducibility and generalizability of the network structure. We used module preservation analysis [40] to compare the identified modules with independent expression profiles from in vivo human brain development and in vitro neuronal differentiation of primary human neural progenitor cells (phNPCs) (Methods). Remarkably, the co-expression structure of 10 modules can be reproducibly identified in either of two independent expression datasets, differentiating phNPCs in vitro [41] or in vivo cortical development from post-conception week (PCW) 4 to 6 months after birth (Table 1; Additional file 2: Figure S1) [41,42]. Given the biological (different cells and tissues) and methodological differences (different RNA preparation and microarrays) between these studies, the correspondence with previous in vivo and in vitro expression data provides important validation of the transcriptional networks we identified in iPSC-derived neural cells.

\section{Network analysis identifies differentiation and activity- dependent expression changes}

We first sought to investigate if the identified co-expression networks recapitulate molecular processes related to neuronal differentiation and neuronal depolarization in general. We used the module eigengene (first principal component of the expression pattern of the corresponding module $[27,37])$ to summarize gene expression trajectories across samples, and evaluated the relationship of the 18 module eigengenes with differentiation and depolarization status. We found 10 modules strongly correlated with neuronal differentiation and nine modules significantly associated with $\mathrm{KCl}$-induced neuronal depolarization (FDR $<0.05$ ), observed in both case and control cell lines (Table 1; Additional file 2: Figure S2). Representative examples with module eigengene trajectories and enriched GO terms are shown in Figure 1.

Importantly, as highlighted above, we found that many of differentiation and depolarization associated modules were present in independent in vivo and in vitro expression data sets (Table 1), providing independent validation for these in vitro iPSC-derived networks. For instance, as compared to in vivo human fetal brain transcriptional networks, the modules corresponding to iPSC-derived cortical neurons faithfully recapitulated biological processes driving in vivo cortical development, including neurogenesis and differentiation (blue and yellow modules), axonogenesis and dendrite growth (turquoise), as well as synaptogenesis (turquoise and green yellow modules) (Figure 1; Table 1; Additional file 2: Figure S3) [41,42]. Additionally, the genes within depolarization-associated modules (brown, tan, green yellow, and midnight blue modules) demonstrated significant overlap with previously defined depolarizationassociated gene sets defined in mouse cortical neurons [46] and human neuroblastoma cells (IMR-32) [45] before and after $\mathrm{KCl}$ treatment (Figure 1J). In particular, the two modules downregulated upon depolarization (brown and $\tan )$ were enriched for $\mathrm{GO}$ categories related to mitochondria, suggesting altered energy consumption upon prolonged neuron depolarization, in agreement with 
A

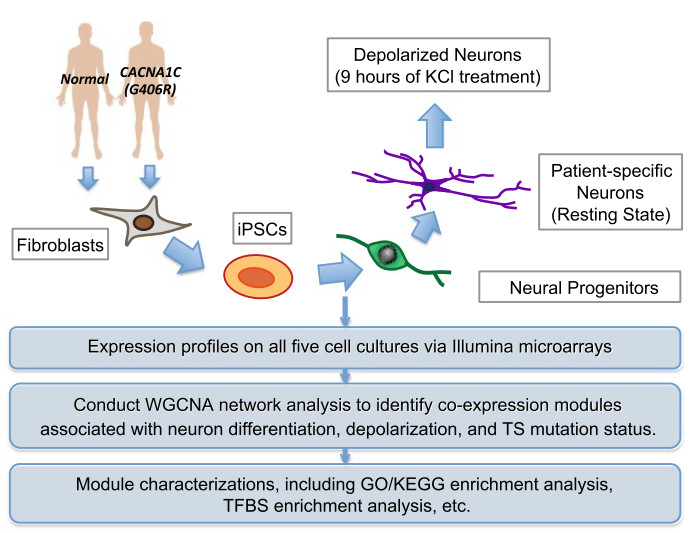

C

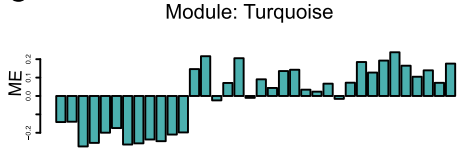

E

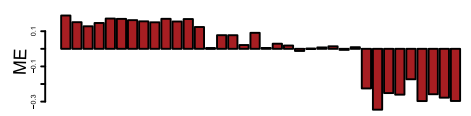

G

Module: Yellow

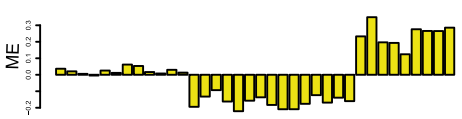
pre-autophagosomal structure
membrane
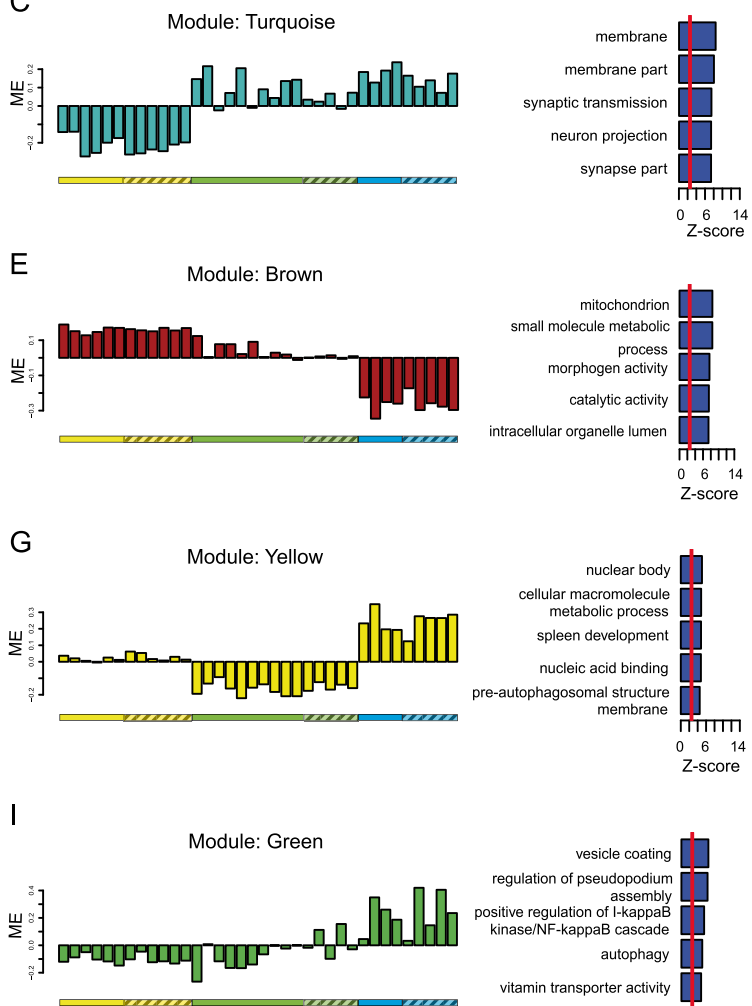

$J$
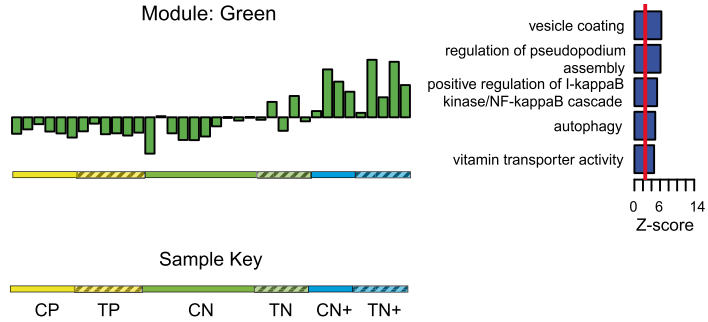

Figure 1 (See legend on next page.)
F Module: Tan
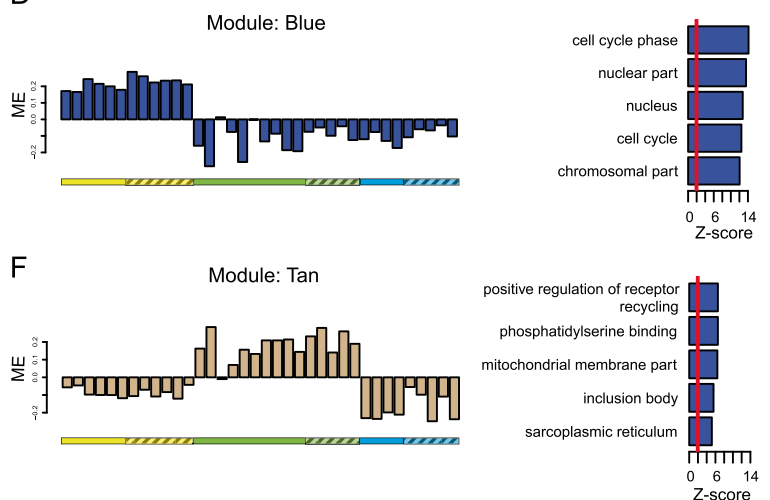

$\mathrm{H}$

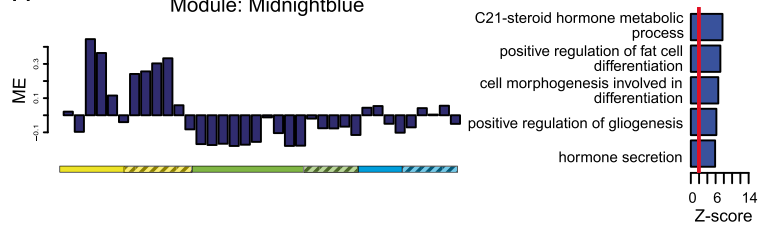

B

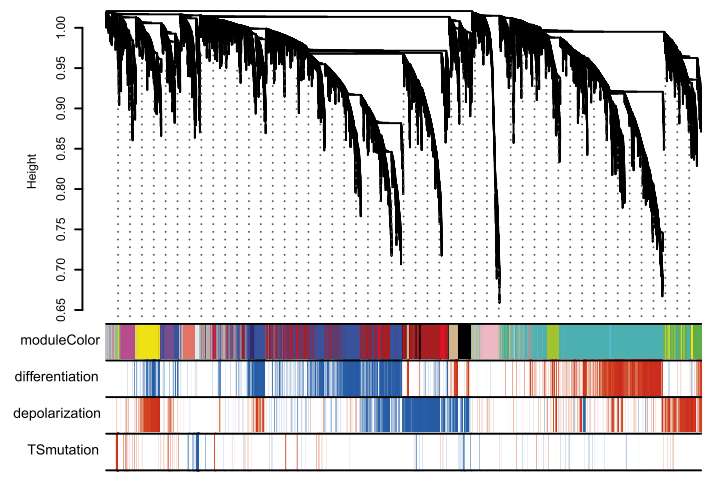

D

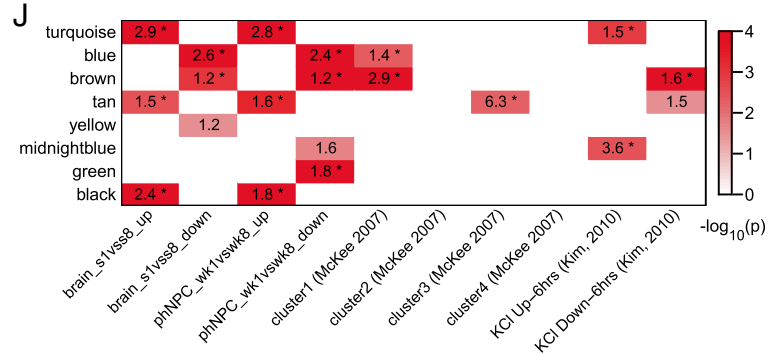


(See figure on previous page.)

Figure 1 WGCNA identifies co-expression modules associated with neuronal differentiation and depolarization. (A) Flowchart illustrating the experimental procedures and expression analysis. (B) Hierarchical clustering of genes based on gene co-expression pattern across progenitors, neurons at rest, and after depolarization. Identified co-expression modules were represented by color classifiers, noted across the top of the dendrogram. The 'differentiation', 'depolarization', and the 'TSmutation' color bars represent the correlation values between gene expression and three biological traits: differentiation, depolarization, and CACNA1C G406R mutation status, respectively. Red signifies upregulation, while blue signifies downregulation. Only the genes with a trait correlation larger than 0.5 or smaller than -0.5 are marked in the plot. (C-I) Module eigengene patterns and enrichment scores of the top five enriched GO categories for module (C) turquoise, (D) blue, (E) brown, (F) tan, (G) yellow, (H) midnightblue, and (I) green. Samples are ordered by control progenitors (CP), patient progenitors (TP), control resting neurons (CN), patient resting neurons (TP), control depolarized neurons (CN+), and patient depolarized neurons, as illustrated by the key at the bottom. (J) Module-level enrichment for previously identified differentiation- and depolarization-associated gene sets curated from: (1) Kang et al. developing postmortem human brain [41,42]; (2) Stein et al. phNPC expression study (phNPC_wk1vswk8_up/down) [41]; (3) McKee et al. [45]; and (4) Kim et al. [46] KCl-induced depolarization expression studies. 'brain_s1vss8_up/down' represent the genes that are either up- or downregulated between stage 1 vs. stage 8, while 'phNPC_wk1vswk8_up/down' are the group of the genes up- or downregulated between week 1 vs. week 8 differentiation, as defined in the paper [41,42]. Cells are colored to reflect enrichment significance with ceiling of $10^{-4}$. Enrichment odds ratios are shown in the table if the $P<0.05$ ( $*$ FD $<0.05$ ).
McKee et al. in human neuroblastoma IMR-32 cells [45]. Together these findings demonstrate the power of WGCNA in identifying generalizable, functionally important gene modules.

Interestingly, a subset of modules was enriched for genes affected by both differentiation and depolarization (Figure 1J; Additional file 3: Table S2), which could provide a molecular basis for modulation of neuronal differentiation by depolarization [58-60]. For instance, the brown module, whose module eigengene showed dramatic down-regulation in depolarized neurons, also followed a significant decrease with neuronal differentiation (Figure 1E). On the other hand, the module eigengenes of the yellow, tan, black, and midnight blue modules, showed opposite directions upon differentiation as compared with depolarization (Figure 1F-H). These observations were consistent with the notion that neuronal plasticity can recapitulate processes involved in neuronal development [61-63].

\section{Gene co-expression modules dissect pathways related to different aspects of TS symptoms}

Next, we asked if we could identify modules associated with TS mutation status, which would provide insight into dysregulation of molecular networks in TS and disease pathophysiology. By comparing the module eigengene patterns across patient and control cells, we identified seven modules that were significantly associated with the TS mutation (FDR <0.05). Remarkably, the top two most disease correlated modules (light green and light cyan; Rsquare $>0.8$; Figure $2 \mathrm{~A}$ and $\mathrm{B}$ ) included dysregulated genes previously implicated in neurodevelopmental diseases, such as YWHAE (Miller-Dieker Syndrome) [64], ERC1 (12p13.31 deletion associated developmental delay) [65], and $V A V 3$ (schizophrenia) [66] (Figure 2B).

A further critical question is: to what extent these TSassociated modules can inform us about the molecular mechanism of TS-related abnormalities? Here, we investigated every module by GO/KEGG enrichment analysis and performed over-representation analysis with respect to curated disease associated genes (Methods). We observed striking enrichment of known ID susceptibility genes [48-51] in two downregulated modules, light cyan and salmon (Figure 2C; Additional file 3: Table S3). Specifically, in the light cyan module, seven ID genes were identified: $L A M P 2$, GK, IDS, CUL4B, AFF2, PDHA1, and SLC16A2 (Fisher's exact test: enrichment odds ratio $(\mathrm{OR})=3.8 ; P=0.004)$. More importantly, these seven ID candidate genes form a sub-cluster within the light cyan module (Figure 2D), suggesting their tight functional dependence. Moreover, this module was enriched for GO categories involved in organelle membrane, and the KEGG pathway of ubiquitin mediated proteolysis, which agrees with previous reports of the causal relationship between impaired proteasomal activity and cognitive disorders, including ID [67]. The salmon module, which contained genes downregulated in cells carrying the TS mutation, was even more enriched for ID susceptibility genes, containing 18 genes known to cause ID $(\mathrm{OR}=3.3, P=3 \mathrm{e}-05)$ (Figure $2 \mathrm{E})$. Together the identification of these two downregulated modules provides an unbiased starting point based on gene expression for exploring the molecular connections between the TS mutation and the molecular mechanisms of ID [9].

In contrast to the salmon and light cyan modules enriched for ID genes, the black downregulated module was enriched for ASD candidate risk genes curated from the SFARI gene database [47] (Figure 2C; Additional file 3: Table S4). Six known ASD candidate susceptibility genes were identified in the black module $(\mathrm{OR}=2.5, P=0.04)$, and three of them, ASTN2, ARNT2, and RPS6KA2, were hubs (Figure $2 \mathrm{H}$ ). More importantly, the top connected genes in the black module ( $\mathrm{kME}>0.7$ ) significantly overlapped with a previously defined co-expression module, called asdM12, identified via unbiased transcriptome analysis in postmortem ASD brains (OR $=2.4, P=0.02)$ [33], but not preserved in control tissues. asdM12, which contains genes involved in synaptic development and 
Table 1 Summary of co-expression modules associated with neuronal differentiation and depolarization, and TS mutation

\begin{tabular}{|c|c|c|c|c|c|c|c|}
\hline \multirow{2}{*}{$\begin{array}{l}\text { Module } \\
\text { color }\end{array}$} & \multicolumn{3}{|c|}{ Trait association $(\mathrm{FDR}<0.05)$} & \multicolumn{2}{|c|}{ Preservation } & \multirow[t]{2}{*}{ Top enriched GOs } & \multirow{2}{*}{$\begin{array}{l}\text { Top } 5 \text { connected } \\
\text { genes by kME }\end{array}$} \\
\hline & Differentiation & Depolarization & TS mutation & In vivo & In vitro & & \\
\hline $\begin{array}{l}\text { Green } \\
\text { yellow }\end{array}$ & $\uparrow$ & $\uparrow$ & & & & $\begin{array}{l}\text { Mammary gland epithelium development, } \\
\text { midbrain - hindbrain boundary development, } \\
\text { hemopoietic stem cell proliferation }\end{array}$ & $\begin{array}{l}\text { LMX1A, RSPO3, } \\
\text { WLS, TM4SF1, } \\
\text { ATF3 }\end{array}$ \\
\hline Turquoise & $\uparrow$ & $\uparrow$ & & Preserved & Preserved & $\begin{array}{l}\text { Synapse part, synaptic transmission, neuron } \\
\text { projection }\end{array}$ & $\begin{array}{l}\text { SNAP25, C12orf68, } \\
\text { MYT1, MAP6, } \\
\text { EEF1A2 }\end{array}$ \\
\hline Black & $\uparrow$ & $\uparrow$ & $\uparrow$ & & & $\begin{array}{l}\text { Nervous system development, nucleobase } \\
\text { catabolic process, hydrolase activity }\end{array}$ & $\begin{array}{l}\text { RPS6KA2, ATP9A, } \\
\text { KIAA1549L, } \\
\text { FAM229B, AKT1 }\end{array}$ \\
\hline Tan & $\uparrow$ & $\downarrow$ & & & Preserved & $\begin{array}{l}\text { Mitochondrial membrane part, } \\
\text { ribonucleoside triphosphate metabolic } \\
\text { process, unfolded protein binding }\end{array}$ & $\begin{array}{l}\text { KIAA0368, ZNF706, } \\
\text { SRI, C9orf169, } \\
\text { OPA1 }\end{array}$ \\
\hline Cyan & $\uparrow$ & & & Preserved & & $\begin{array}{l}\text { Skeletal muscle thin filament assembly, } \\
\text { platelet-derived growth factor binding, } \\
\text { actin-mediated cell contraction }\end{array}$ & $\begin{array}{l}\text { CAV1, SPP1, ME1, } \\
\text { SPP1, VSX1 }\end{array}$ \\
\hline Grey60 & $\uparrow$ & & & & & $\begin{array}{l}\text { De novo' post-translational protein folding, } \\
\text { mitochondrion, mitochondrial part }\end{array}$ & $\begin{array}{l}\text { TBCE, EBNA1BP2, } \\
C C T 4, A S P H, A K 2\end{array}$ \\
\hline $\begin{array}{l}\text { Midnight } \\
\text { blue }\end{array}$ & $\downarrow$ & $\uparrow$ & & & & $\begin{array}{l}\text { Cell morphogenesis involved in } \\
\text { differentiation, C } 21 \text {-steroid hormone } \\
\text { metabolic process, positive regulation of fat } \\
\text { cell differentiation }\end{array}$ & $\begin{array}{l}\text { TPD52L1, GJA1, } \\
\text { BMP2, IL17RD, } \\
\text { KRT15 }\end{array}$ \\
\hline Yellow & $\downarrow$ & $\uparrow$ & & Preserved & & $\begin{array}{l}\text { Nuclear body, positive regulation of cell } \\
\text { growth, Golgi vesicle transport }\end{array}$ & $\begin{array}{l}\text { MRPS6, PCID2, } \\
\text { PPP6C, GBA2, } \\
\text { SETD4 }\end{array}$ \\
\hline Brown & $\downarrow$ & $\downarrow$ & & Preserved & Preserved & $\begin{array}{l}\text { Intracellular organelle lumen, oxidation- } \\
\text { reduction process, NADH dehydrogenase } \\
\text { complex }\end{array}$ & $\begin{array}{l}\text { DOCK1, COMMD4, } \\
\text { STRADB, SLC16A9, } \\
\text { ORC3 }\end{array}$ \\
\hline Blue & $\downarrow$ & & & Preserved & Preserved & Cell cycle phase, cell division, nuclear division & $\begin{array}{l}\text { NIF3L1, LIN28A, } \\
\text { TEX10, AMMECR1, } \\
\text { NCAPG }\end{array}$ \\
\hline Green & & $\uparrow$ & & & Preserved & $\begin{array}{l}\text { Vesicle coating, positive regulation of } \\
\text { I-kappaB kinase/NF-kappaB cascade, } \\
\text { autophagy }\end{array}$ & $\begin{array}{l}\text { NUP98, DNAJA1, } \\
\text { DHX37, ETNK1, } \\
\text { CGGBP1 }\end{array}$ \\
\hline Red & & $\downarrow$ & $\uparrow$ & Preserved & Preserved & $\begin{array}{l}\text { Nucleobase metabolic process, nuclease } \\
\text { activity, proteasome core complex }\end{array}$ & $\begin{array}{l}\text { USP13, PSMG1, } \\
\text { RTN4IP1, PTCD2, } \\
\text { PSMG1 }\end{array}$ \\
\hline $\begin{array}{l}\text { Light } \\
\text { green }\end{array}$ & & & $\uparrow$ & & & $\begin{array}{l}\text { tRNA processing, positive regulation of lipid } \\
\text { metabolic process, response to virus }\end{array}$ & $\begin{array}{l}\text { CRYBB2, SNHG5, } \\
\text { EXOC1, IFITM2, } \\
\text { VAV3 }\end{array}$ \\
\hline Magenta & & & $\uparrow$ & & & $\begin{array}{l}\text { Type } 1 / 2 \text { fibroblast growth factor receptor } \\
\text { binding; neuron recognition; growth factor } \\
\text { activity }\end{array}$ & $\begin{array}{l}\text { CTSF, ZNF626, } \\
\text { ZNF521, PLEKHA5, } \\
\text { COLAA6 }\end{array}$ \\
\hline Purple & & & $\uparrow$ & Preserved & Preserved & $\begin{array}{l}\text { ncRNA processing; nuclear body, } \\
\text { ribonucleoprotein complex biogenesis }\end{array}$ & $\begin{array}{l}\text { RRS1, RRP15, } \\
\text { PUS1, NOLC1, } \\
\text { ABCE1 }\end{array}$ \\
\hline $\begin{array}{l}\text { Light } \\
\text { cyan }\end{array}$ & & & $\downarrow$ & & & $\begin{array}{l}\text { Lytic vacuole, integral to organelle } \\
\text { membrane }\end{array}$ & $\begin{array}{l}\text { TRAPPC2, ZNF177, } \\
\text { HLA-A, ZNF559, } \\
\text { RPS26P47 }\end{array}$ \\
\hline Salmon & & & $\downarrow$ & & & $\begin{array}{l}\text { Actin filament bundle assembly, regulation of } \\
\text { establishment of protein localization in } \\
\text { plasma membrane, regulation of type I } \\
\text { interferon-mediated signaling pathway }\end{array}$ & $\begin{array}{l}\text { NDUFB11, MSN, } \\
\text { UPRT, GPKOW, } \\
\text { TSR2 }\end{array}$ \\
\hline
\end{tabular}


B

A

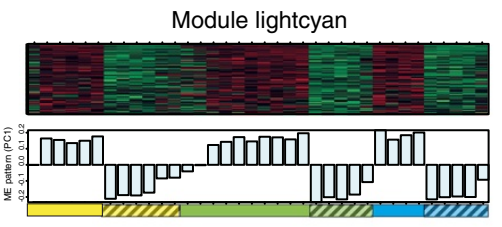

Module lightgreen

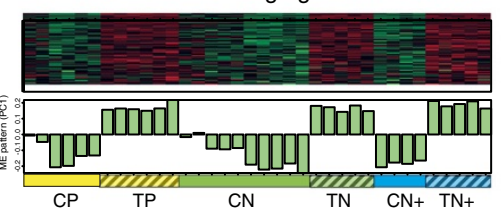

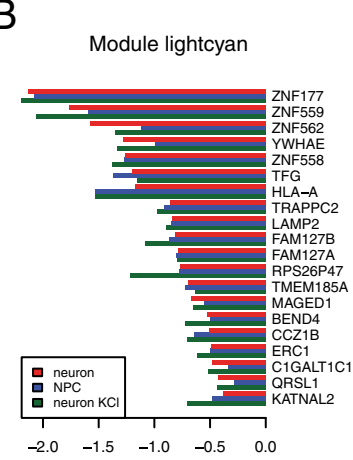

$\log _{2}$ Fold Changes

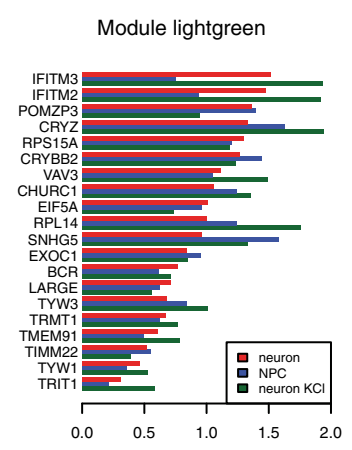

$\log _{2}$ Fold Changes

C

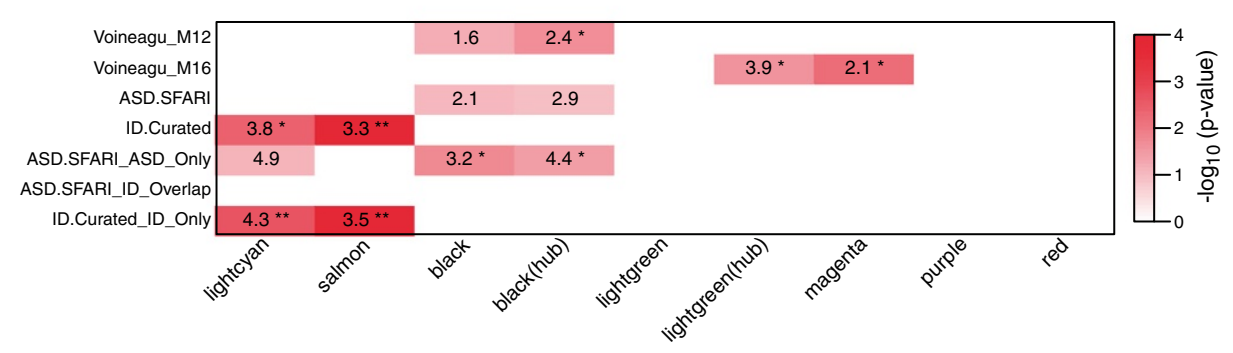

D Module: Lightcyan

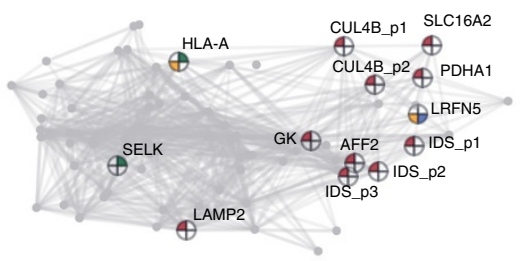

F Module: Lightgreen

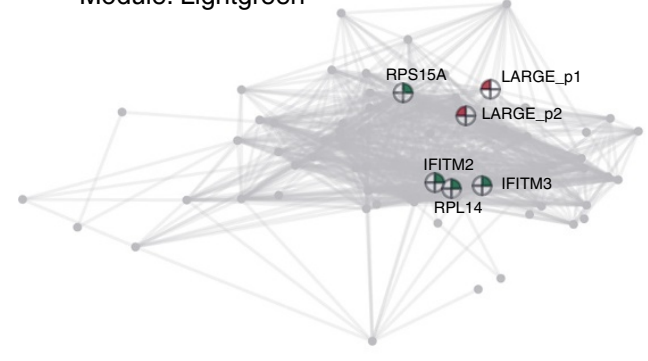

H Module: Black

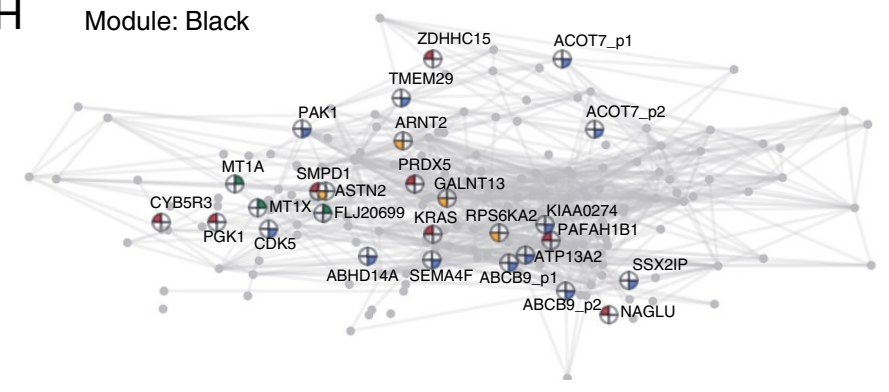

E Module: Salmon

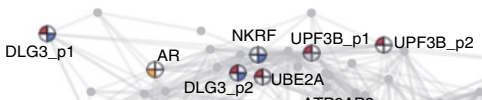

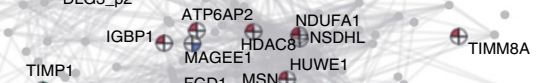

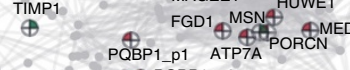

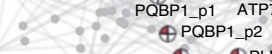

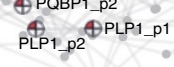

$$
\begin{aligned}
& \mathrm{SP} 110 \_\mathrm{P} 1 \oplus \oplus \oplus^{\mathrm{SP} 110 \_\mathrm{p} 2}
\end{aligned}
$$

\section{G Module: Magenta}

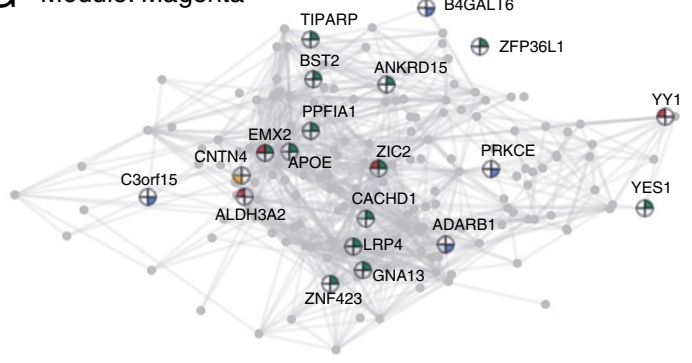

Figure 2 (See legend on next page.) 
(See figure on previous page.)

Figure 2 Gene co-expression modules associated with the TS mutation. (A) Heatmap showing expression pattern of the module genes and a barplot showing the module eigengene pattern across samples for the light cyan and light green modules. (B) Log 2 transformed fold changes of the top 20 connected genes in the light cyan and light green modules in cases as compared to controls at the three experimental stages. (C) Module-level enrichment for previously identified ASD and ID associated genes. Enrichment odds ratios are shown in the table if the $P<0.1$ $\left({ }^{*} P<0.05,{ }^{*} F D R<0.05\right)$. (D-H) Visualization of the co-expression network among the top connected genes (kME >0.6 or top 200 depending on which one is smaller) based on multidimensional scaling of their pairwise co-expression correlations in the (D) light cyan, (E) salmon, (F) light green, (G) magenta, and $\mathbf{( H )}$ black module. Genes with multiple probes are labeled separately. Pie chart: ID susceptibility genes (red); ASD susceptibility genes from the SFARI database (yellow) [47]; genes in the Voineagu et al. asdM12 module (purple) [33]; genes in the Voineagu et al. asdM16 module (green) [33]. Only the top 1,000 connections are shown in each module.

function, was downregulated in cerebral cortex from ASD subjects, in parallel with the observed decrease of the black module genes in TS observed here. Consistent with asdM12 annotation, the black module also was enriched for postsynaptic density (PSD) associated genes [68] $(\mathrm{OR}=1.9$, $P=0.001)$ that are critical regulators of synaptic signaling and plasticity. These observations suggest convergent synaptic dysfunction in this monogenic form of ASD caused by TS studied here and idiopathic ASD more broadly. The non-overlapping relationship of known ID and ASD susceptibility genes to specific modules was also consistent with recent work demonstrating differing in vivo expression patterns of genes causing these two clinically distinct conditions [34].

We next evaluated the upregulated modules in TS neurons. As shown in Figure 2C, the light green and magenta modules show significant overlap with asdM16, a module of genes upregulated in ASD postmortem brain [33] (Additional file 3: Table S5). The biological functions enriched in this module include immune response, which is consistent with immune dysfunction observed in TS $[9,10,69]$. In particular, 18 genes in the ASD postmortem asdM16 module were identified in the magenta module, and four were identified in the light green module (Figure 2F-G). Remarkably, IFITM2 and IFITM3, two interferon response genes that have been shown to be the hub genes in asdM16 [33], were also identified as hubs in this light green module, showing parallel dysregulation in ASD and TS patients. In the light green module, we also identified INPP5E, a gene involved in phosphatidylinositol signaling system and known to mobilize intracellular calcium. Mutation of this gene leads to Joubert syndrome, which is a rare monogenic condition with high penetrance for ASD [70-73]. In summary, both down- and upregulated modules in TS show changes parallel with those observed in postmortem brain of idiopathic ASD, consistent with the existence of convergent molecular pathways in multiple forms of ASD [74].

\section{Network analysis reveals differentiation defects in TS}

We previously showed that the cell lines derived from TS patients had abnormalities in differentiation at the cellular level [25]. Here, we sought to investigate if we can use the unbiased transcriptomic approach to find the molecular mechanisms driving this differentiation deficit. By comparing the module eigengene expression patterns during neuronal differentiation across TS and control cells, we observed that the black module was upregulated upon differentiation in controls, but not in patient cells (Figure 3A and B). Comparison of expression fold changes of the top 15 connected genes in the black module during the progenitor to neuron transition are shown in Figure 3C, demonstrating the dramatic attenuation in differentiation related expression changes in patient versus control neurons. This parallels with the overlap of black module genes with asdM12, which as described above, is down regulated in post mortem ASD brain versus control [25].

To further characterize the differentiation abnormalities in the TS patient cells, we used a factor design to identify genes showing altered expression trajectories during differentiation in TS and control cells (Methods). We identified 1,155 genes with a significant interaction effect between developmental stage and disease status $(P<0.05)$. By carefully evaluating their expression patterns in patient and controls samples (Methods), we further classified these genes into four categories: (1) genes downregulated upon differentiation in control but not in TS cells (128 genes); (2) genes upregulated upon differentiation in control but not in TS cells (163 genes); (3) genes downregulated upon differentiation in TS cells but not in control (141 genes); and (4) genes upregulated upon differentiation in TS cells but not in control (156 genes). The 15 genes with largest difference between cases and controls in each group are displayed in Figure 3D. As expected, the black module significantly overlapped with controlspecific upregulated genes (hypergeometric test; $P=2.39 \mathrm{e}-6$ ), again consistent with a defect in synaptic differentiation in TS.

We also found, not unexpectedly, that these four groups of genes with distinct disease and differentiation trajectories manifest distinct functional ontologies. For instance, genes that were downregulated in control neurons, but not in TS neurons, were enriched for functional categories related to cell cycle control, DNA replication, and cell proliferation (Figure 3D). This suggests a defect in the cell cycle of TS neural progenitors 


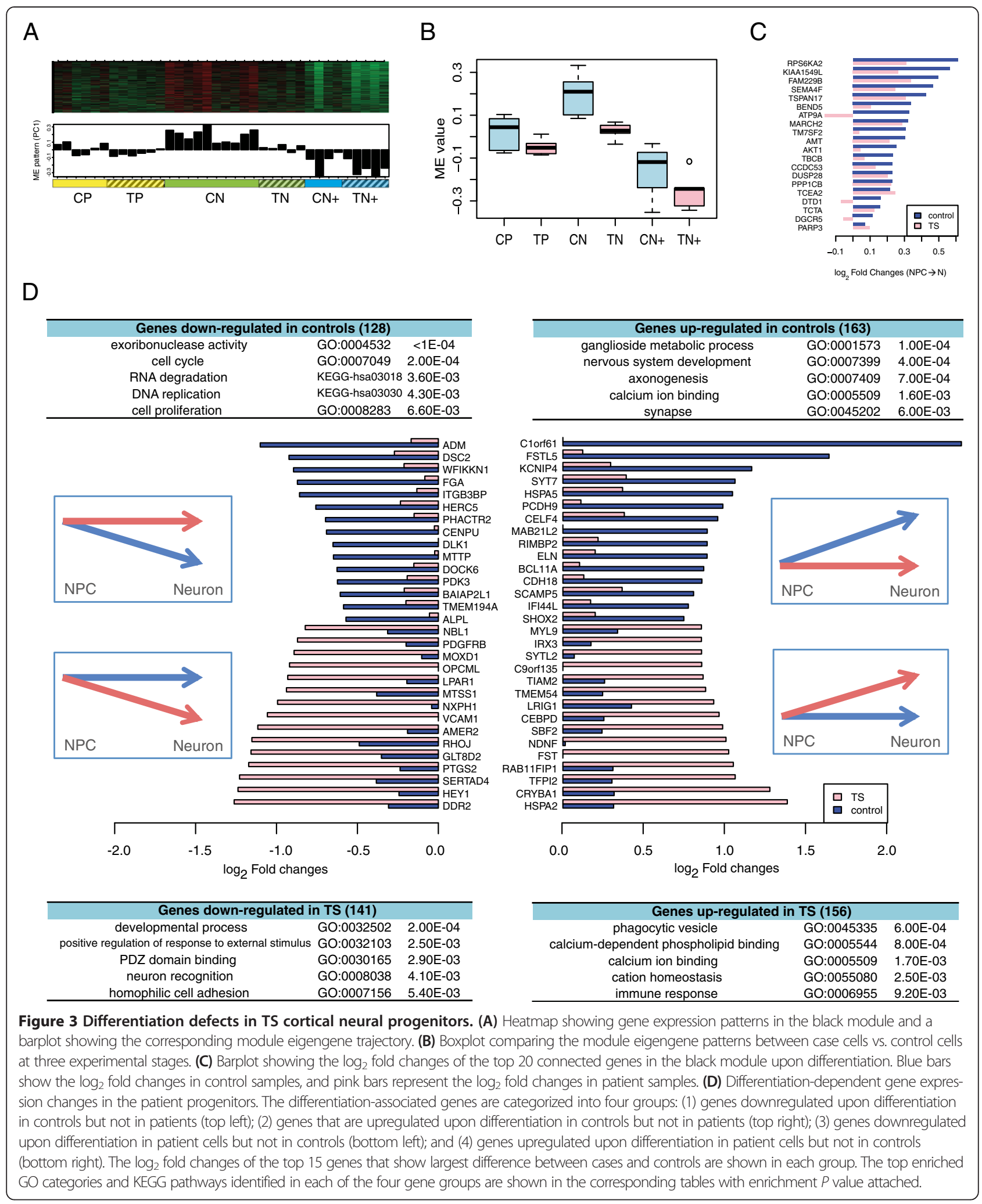

that could contribute to the corticogenesis defects we have previously demonstrated [25]. On the other hand, genes, such as CTNNA2, SNCA, and SYT7, exhibit control-specific upregulation pointing to pathways related to synaptic function, axonogenesis, and nervous system development (Figure 3D). Similarly, the genes 
exclusively down-regulated upon differentiation in TS patient cells were enriched for the GO categories of neuron recognition, PDZ domain binding, and homophilic cell adhesion, all involved in synaptic development, including $C A D M 1, F E Z F 2$, and $O P C M L$ (Figure 3D). In addition, the GO terms enriched among TS-specific upregulated genes were related to cation homeostasis control, and calcium ion binding activities, such as AGTR1, ANXA7, and ITSN1 (Figure 3D), which were consistent with the biophysical dysfunction of the ion channels carrying the TS mutation. Taken together, our findings suggest a global effect of the CACNA1C G406R mutation on neuronal differentiation and point to specific pathways and genes that warrant further experimental study.

\section{TS associated co-expressed genes are co-regulated by calcium-dependent transcription factors}

As shown in Paşca et al., increased $\left[\mathrm{Ca}^{2+}\right]_{\mathrm{i}}$ elevations were observed in TS-derived neural progenitors and neurons after depolarization [25]. Thus we investigated how the identified TS-associated expression features could be related back to the causal TS calcium channel mutation and corresponding changes in $\left[\mathrm{Ca}^{2+}\right]_{\mathrm{i}}$ signaling. It is known that calcium influx regulates activity-dependent gene expression through a hierarchical transcription network acting through multiple signaling cascades $[3,75]$. While simple lists of up- and downregulated genes may not provide power to identify regulatory mechanisms, we hypothesized that these tight co-expression modules would reflect calcium-dependent co-regulation. To test this, we performed transcription factor binding site (TFBS) motif enrichment analysis on the seven TS associated modules to investigate whether those modules were enriched for any calcium-dependent transcriptional regulators (Methods).

For each module, we identified a set of transcription factor binding sites enriched within a $1 \mathrm{~kb}$ window upstream of the transcription start site, providing strong evidence for the co-regulation hypothesis. Moreover, this TFBS analysis identified four important calcium-regulated transcription factor families in the TS related modules: NFAT [19,20], MEF2 [17,18], CREB [21-24], and FOXO [29-32]. Among them, FOXO proteins, which regulate neuronal polarization and positioning [76] and synaptic function and memory consolidation [30], have binding targets enriched in six out of seven TS-associated modules (light cyan, salmon, magenta, black, purple, and red) (Figure 4). A total of 1,249 predicted targets were identified in these six modules, and 229 of them were validated through data from chromatin immunoprecipitation (ChIP) experiments [55-57], providing a significant validation of the bioinformatic predictions (hypergeometric test; $P=7.73 \mathrm{E}-12$; Methods).

The other TF enrichments were limited to smaller subsets of modules. Perhaps most remarkable is the enrichment of NFAT targets in two modules upregulated in TS, magenta and light green (also asdM16 associated, which is upregulated in idiopathic ASD [33]; Figure 4). Four of the five members in this protein family, NFATc1, NFATc2, NFATc3, and NFATc4, are known to be regulated via calcium signaling $[19,20,77,78]$. Forty-two genes $(68 \%)$ in the light green module and 262 genes (82\%) in the magenta module were predicted to contain at least one NFAT binding site in their promoter regions. No ChIP data are available from developing neurons, but in lymphoblasts $[55,56]$, we were able to observe direct binding to 25 neuronal targets (hypergeometric test; $P=2.02 \mathrm{E}-2$ ). Taken together, these results suggest that the two upregulated modules (light green and magenta), which also represent the convergence of TS and ASD at the level of gene expression, are likely to be mediated via the calcium/NFAT signaling pathway.

MEF2, a well-studied calcium or neuronal activity dependent transcription factor family number $[3,17,18]$, was enriched in the promoter regions within genes contained in four TS associated modules: black (downregulated in TS and with activity, asdM12 associated), magenta (upregulated in TS, asdM16 associated), purple, and red (Figure 4). Of the four different MEF2 family members, MEF2A, MEF2B, MEF2C, and MEF2D, three (MEF2A/C/ D) had their binding sites enriched in all four modules. Specifically, 309 genes (76.5\%) in the black module, 246 genes $(77 \%)$ in the magenta module, 214 genes $(75 \%)$ in the purple module, and 354 genes (77\%) in the red module contain at least one MEF2 binding site. Using experimental ChIP-seq and ChIP-chip data [55-57], we were able to validate a total of 358 predicted MEF2 binding targets (hypergeometric test; $P=6.58 \mathrm{E}-20$ ) (Methods). Remarkably, MEF2A and MEF2C were previously reported to have binding sites enriched in idiopathic ASD associated co-expression modules, consistent with the notion of involvement of activity-dependent dysregulation in idiopathic ASD pathogenesis [3,34].

Targets of two CREB proteins, CREB1 and CREB2, were also enriched in the black (downregulated in TS and with activity, asdM12 associated), and magenta (upregulated in TS, asdM16 associated) modules (Figure 4). CREB transcription factors bind to the cAMP-responsive element (CRE), and are regulated by calcium influx [1,21-23,79]. One hundred and sixty-one (40\%) genes in the black module and 134 genes (42\%) in the magenta module were predicted to have at least one CREB binding site, 164 of which could be validated through available ChIP experiments [55-57] (hypergeometric test; $P=4.15 \mathrm{E}-63$ ) (Methods). Moreover, we observed overlap of the predicted targets between the CREB-transcriptional machinery and the MEF2 proteins (Additional file 2: Figure S4), although their binding motifs are quite different. One hundred and forty-eight genes have at least one predicted binding site 


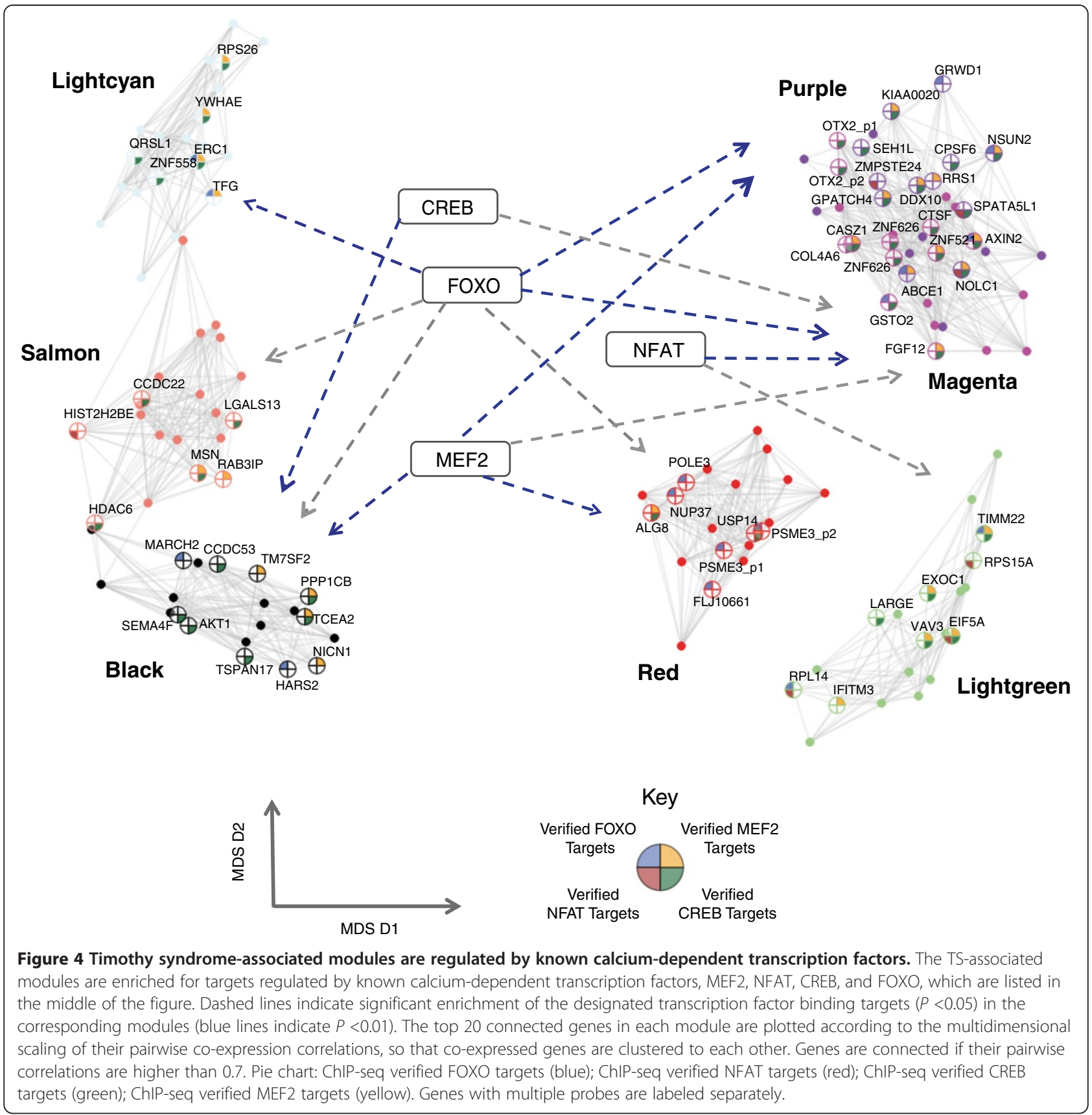

for both MEF2 and CREB proteins in the black module and 123 (39\%) in the magenta module, respectively, strongly implicating a synergistic interaction between the two pathways upon calcium influx.

Taken together, our results not only demonstrate significant co-regulation among the co-expressed genes, but also provide specific regulatory links for associating distinct co-expression modules. More importantly, these findings provide a path for bridging the observed downstream transcriptional alterations back to the mutation in the L-type calcium channel Cav1.2 via their regulation by calcium dependent transcription factors.

\section{Discussion}

TS is a rare and complex disorder characterized by a broad spectrum of phenotypic abnormalities. There are few TS patients available for study and the data used here represent the only gene expression data set available in this disorder. Here, we studied multiple cell lines from independent differentiation experiments with four 
control iPSC clones from two normal subjects, four TS iPSC clones from one TS patient carrying a dominantly acting mutation, and one human embryonic stem cell line (H9; additional control) to mitigate the concerns about the effect of induction of pluripotency, or other confounding factors that could bias the results. Through analysis of data from iPSC-derived cortical neural progenitors and neurons, we identified distinct gene expression modules that are associated with human neuronal differentiation and neuronal depolarization across all conditions. We further demonstrate that the networks identified in control and TS iPSC-derived neural progenitors and neurons can be validated in independent in vitro and in vivo data sets. Moreover, we identified several co-expression modules that were correlated with TS mutation status, highlighting potential molecular pathways that may contribute to distinct phenotypic aspects of TS. Remarkably, by integrating the transcriptional networks defined by our co-expression analysis with TFBS enrichment analysis, we showed that the TSassociated expression changes are co-regulated by a set of calcium-dependent transcriptional factors. Furthermore, many of the specific genes and processes identified here in this monogenic condition overlap with those identified in postmortem brains from patients with idiopathic ASD. Consequently, the module hub genes and the identified transcription factors provide an important source of new candidate genes for therapeutic targeting. These intriguing results indicate that study of additional TS patient lines, when available, will be valuable.

As with other single gene disorders, how a mutation in a single gene yields such pleotropic CNS phenotypes provides a significant challenge [80]. Here, our bio-informatic analysis links specific molecular pathways perturbed in TS neurons to different aspects of TS, including ID, alterations in immune response, and behavioral phenotypes overlapping with ASD [8-10]. The identification of modules highly enriched for genes that either cause or increase risk for ID and ASD, provides new avenues to investigate the pathways that may mediate divergence between these disorders [34]. In particular, the enrichment for genes that were dysregulated in idiopathic ASD brain (asdM12 and asdM16) [33] demonstrates the existence of previously suggested convergent molecular pathways in idiopathic ASD in this monogenic highly penetrant form of ASD [33-35]. In parallel with recent findings, our analysis also indicates distinct modules associated with ASD (black, light green, and magenta) and ID (light cyan, salmon), consistent with divergent molecular mechanisms for ASD and ID [34]. Our analysis also prioritizes important gene sets (module hub genes) and pathways for further analyses. These genes can be helpful to understand how diverse genetic syndromes converge on ASD and how they are modulated. For example, two interferon response genes, IFITM2 and IFITM3, that are dysregulated in ASD brains [33] and the light green module in TS, as well as RPS6KA2 and AKT1 in the black module, highlight potential convergent molecular links between TS and ASD that warrant future experimental investigation.

Network analysis allowed us to determine diseaseassociated alterations at the level of transcriptional coregulation. TFBS enrichment analysis prioritized several candidate transcription factors as putative regulators of disease-associated modules, most of which could be confirmed by experimental data. These findings provide direct evidence for our hypothesis that module gene co-regulation reflects transcription factor binding. More importantly, our analysis identified four known calcium-dependent gene transcription factor families that regulate key genes within these modules: FOXO [29-31], NFAT [19,78], MEF2 [17,18], and CREB [21-23]. Moreover, by showing the overlap of the TF targets within modules, our analysis also implicates coordination among those calcium-dependent transcriptional regulation pathways. In particular, we predict a synergistic effect between MEF2 and CREB proteins in TS cells, consistent with the observation that phosphorylation of both MEF2 and CREB proteins leads to recruitment of CREB-binding protein $(\mathrm{CBP})$ to activate downstream transcription [81]. Lastly, since several modules regulated by these calcium-dependent pathways are also associated with ASD, these data support previous suggestions that dysregulation of activity-dependent signaling plays a more general role in ASD pathogenesis [3].

Also, of note, our analysis also highlights the potential role for RSK (ribosomal S6 kinase) proteins as putative regulators of genes in the black module. RSK proteins have been implicated in disorders of cognition and behavior, and mutations in RSK2 lead to Coffin-Lowry syndrome, an X-linked dominant genetic disorder that causes severe mental problems [82]. RPS6KA2 (also known as ribosomal s6 kinase 3, RSK3), RPS6KA4, and AKT1, all kinases that are known to regulate CREB [79,83-86], were identified in the black module, where RPS6KA2 and AKT1 were hub genes. Additionally, several known RSK and AKT substrates were found in the black module, including GSK3A, BEX1, CTNND2, and PAK1, which were centrally located in the protein-protein interaction network of the black module (Additional file 2: Figure S5). These observations lead us to speculate that RSK3/AKT1/ CREB have key regulatory roles in the black module, and that downregulation of the black module in TS samples is due to downregulation of RSK/AKT pathways, a hypothesis that can be directly tested through experimental investigation.

Neuronal development signaling and plasticity depends on electrical activity [3,61-63]. For instance, $\mathrm{KCl}$-mediated depolarization of neurons changes the chromatin accessibility of several differentiation-associated genes, such as 
$N C A M$ and $T H$, and can subsequently alter the differentiation path of neurons $[58,60]$. However, neuronal depolarization has rarely been investigated at the genomewide scale in human derived neural progenitors and neurons. Here, we identified five modules (brown, tan, yellow, midnight blue, and black) that were highly correlated with both differentiation and depolarization, providing a molecular network connecting these processes. An illustrative example is the black module, which is associated with the TS mutation, and was upregulated upon differentiation and downregulated upon depolarization. Importantly, as implicated by the black module trajectory, TS derived neural progenitors exhibited significant differentiation deficits, strongly implicating the involvement of $\mathrm{Ca}_{\mathrm{v}} 1.2$ in neural development. This is supported by changes in several genes involved in cation homeostasis control, including AGTF1, ANXA7, CD55, HMOX1, SFXN4, SLC11A2, SLC39A14, and SLC4A11, which were exclusively upregulated in TS progenitors upon differentiation, consistent with large-scale changes in the molecular networks associated with differentiation in TS.

\section{Conclusions}

Our results define a transcriptional network outlining a shared molecular basis for cortical neural differentiation and neuronal depolarization, but also implicate dysregulation of these common molecular pathways in TS pathogenesis. We show that several of these molecular pathways dysregulated by this specific $\mathrm{Ca}_{\mathrm{v}} 1.2$ mutation are shared with idiopathic ASD based on comparison with data from in vivo brain gene expression. By defining the core molecular changes downstream of the $\mathrm{Ca}_{\mathrm{v}} 1.2$ mutation and its transcriptional regulators, this work illustrates how an integrative approach can be applied to functionally characterize transcriptional co-regulation under physiological and disease states, and to generate hypotheses to drive further mechanistic experimental investigation.

\section{Additional files}

Additional file 1: Table S1. Module assignment and module membership (kME) for all probes that passed the robust expression criteria.

Additional file 2: Figure S1. Module-based preservation in independent expression data sets from human brain development and neuron differentiation in vitro. Figure S2. Module eigengene correlation with neuron differentiation and depolarization, as well as the TS mutation status. Figure S3. Module-level enrichment for in vivo defined modules during fetal brain development $[41,42]$. Figure S4. Overlap of MEF2 and CREB predicted targets. Figure S5. A protein-protein interaction network comprises the top connected genes in the black module (kME >0.7) [87].

Additional file 3: Table S2. Statistic significance of module-level enrichment for previously identified differentiation- and depolarizationassociated gene sets. Odds ratio, $P$ value, and Benjamini-Hochberg $(\mathrm{BH})$ corrected FDR for significant overlap at $P<0.05$ are shown. Table S3. Statistic significance of module-level enrichment for previously identified ASD and ID associated genes. Odds ratio, $P$ value, and $\mathrm{BH}$ corrected FDR for significant overlap at $P<0.1$ are shown. Table S4. A table listing ID susceptibility genes in the light cyan and salmon modules. Table S5. A table listing ASD associated genes in the black, light green, and magenta modules.

\section{Abbreviations}

ASD: Autism spectrum disorders; ChIP: Chromatin immunoprecipitation; GO: Gene ontology; ID: Intellectual disability; iPSC: Induced pluripotent stem cell; ME: Module eigengene; PCW: Post-conception week; phNPC: Primary human neural progenitor cells; TFBS: Transcription factor binding site; TS: Timothy syndrome; WGCNA: Weighted gene co-expression network analysis.

\section{Competing interests}

The authors declare that they have no competing interests.

\section{Authors' contributions}

YT and DHG designed the study and wrote the manuscript. YT performed WGCNA, differential expression analysis, gene set over-representation analysis, and TFBS enrichment analysis. IV participated in original study design and execution, performed the quality control on the microarray expression data, and contributed to the WGCNA. SPP and RED generated the cell lines. HW contributed to module characterization and interpretation of the data. VC participated in the TFBS enrichment analysis. SH supervised the WGCNA. All authors discussed the results, commented on and approved the manuscript.

\section{Acknowledgements}

We are grateful to A. Suleman for technical support on TFBS enrichment analysis; N. N. Parikshak, and L. de la Torre-Ubieta for helpful discussions and critical reading of the manuscript. This work is supported by NIMH grants to DHG (5R01MH094714, 5R37MH060233, MERiT award, and 5R01MH100027, Autism Center for Excellence network grant). YT was supported by fellowships from the China Scholarship Council and UCLA Graduate Division's Dissertation Year Fellowship.

\section{Author details}

${ }^{1}$ Neurogenetics Program, Department of Neurology, Center for Autism Research and Treatment, Semel Institute, David Geffen School of Medicine, University of California, Los Angeles, CA 90095, USA. ${ }^{2}$ Interdepartmental Ph.D. Program in Bioinformatics, University of California, Los Angeles, CA 90095, USA. ${ }^{3}$ School of Biotechnology and Biomolecular Sciences, University of New South Wales, Sydney, NSW 2052, Australia. ${ }^{4}$ Department of Psychiatry \& Behavioral Sciences, Center for Sleep Sciences and Medicine, Stanford University School of Medicine, Stanford, CA 94305, USA. ${ }^{5}$ Department of Human Genetics, David Geffen Sch. of Medicine, UCLA, Los Angeles, CA, USA. ${ }^{6}$ Department of Neurobiology, Stanford University, Stanford, CA 94305-5345, USA. ${ }^{7}$ Novartis Institutes for Biomedical Research, Cambridge, MA 02139, USA

Received: 25 June 2014 Accepted: 15 September 2014

Published online: 10 October 2014

\section{References}

1. Bading $\mathrm{H}$ : Nuclear calcium signalling in the regulation of brain function. Nat Rev Neurosci 2013, 14:593-608.

2. Catterall WA, Leal $K$, Nanou E: Calcium channels and short-term synaptic plasticity. J Biol Chem 2013, 288:10742-10749.

3. Ebert DH, Greenberg ME: Activity-dependent neuronal signalling and autism spectrum disorder. Nature 2013, 493:327-337.

4. Bading H, Ginty DD, Greenberg ME: Regulation of gene expression in hippocampal neurons by distinct calcium signaling pathways. Science 1993, 260:181-186.

5. Bhat S, Dao DT, Terrillion CE, Arad M, Smith RJ, Soldatov NM, Gould TD: CACNA1C (Cav1.2) in the pathophysiology of psychiatric disease. Prog Neurobiol 2012, 99:1-14.

6. Dolmetsch RE, Pajvani U, Fife K, Spotts JM, Greenberg ME: Signaling to the nucleus by an L-type calcium channel-calmodulin complex through the MAP kinase pathway. Science 2001, 294:333-339.

7. Barrett CF, Tsien RW: The Timothy syndrome mutation differentially affects voltage- and calcium-dependent inactivation of CaV1.2 L-type calcium channels. Proc Natl Acad Sci U S A 2008, 105:2157-2162. 
8. Splawski I, Timothy KW, Sharpe LM, Decher N, Kumar P, Bloise R, Napolitano C, Schwartz PJ, Joseph RM, Condouris K, Tager-Flusberg H, Priori SG, Sanguinetti MC, Keating MT: Ca(V)1.2 calcium channel dysfunction causes a multisystem disorder including arrhythmia and autism. Cell 2004, 119:19-31.

9. Splawski I, Timothy KW, Priori SG, Napolitano C, Bloise R: Timothy Syndrome. In GeneReviews(R). Edited by Pagon RA, Adam MP, Ardinger HH, Bird TD Dolan CR, Fong CT, Smith RJH, Stephens K. Seattle, WA: University of Washington; 1993-2014.

10. Ruan Y, Bloise R, Napolitano C, Priori SG: L-Type Calcium Channel Disease. In Electrical Diseases of the Heart. London: Springer; 2013:209-217.

11. Hoischen A, Krumm N, Eichler EE: Prioritization of neurodevelopmental disease genes by discovery of new mutations. Nat Neurosci 2014, 17:764-772.

12. Murdoch JD, State MW: Recent developments in the genetics of autism spectrum disorders. Curr Opin Genet Dev 2013, 23:310-315.

13. O'Roak BJ, Vives L, Fu W, Egertson JD, Stanaway IB, Phelps IG, Carvill G, Kumar A, Lee C, Ankenman K, Munson J, Hiatt JB, Turner EH, Levy R, O'Day DR, Krumm N, Coe BP, Martin BK, Borenstein E, Nickerson DA, Mefford HC, Doherty D, Akey JM, Bernier R, Eichler EE, Shendure J: Multiplex targeted sequencing identifies recurrently mutated genes in autism spectrum disorders. Science 2012, 338:1619-1622.

14. Cross-Disorder Group of the Psychiatric Genomics Consortium: Identification of risk loci with shared effects on five major psychiatric disorders: a genome-wide analysis. Lancet 2013, 381:1371-1379.

15. Tao X, West AE, Chen WG, Corfas G, Greenberg ME: A calcium-responsive transcription factor, CaRF, that regulates neuronal activity-dependent expression of BDNF. Neuron 2002, 33:383-395.

16. West AE: Biological functions and transcriptional targets of CaRF in neurons. Cell Calcium 2011, 49:290-295.

17. Mao Z, Bonni A, Xia F, Nadal-Vicens M, Greenberg ME: Neuronal activitydependent cell survival mediated by transcription factor MEF2. Science 1999, 286:785-790.

18. Potthoff MJ, Olson EN: MEF2: a central regulator of diverse developmental programs. Development 2007, 134:4131-4140.

19. Crabtree GR, Olson EN: NFAT signaling: choreographing the social lives of cells. Cell 2002, 109:S67-S79.

20. Nguyen T, Di Giovanni S: NFAT signaling in neural development and axon growth. Int J Dev Neurosci 2008, 26:141-145.

21. Hardingham GE, Arnold FJ, Bading H: Nuclear calcium signaling controls CREB-mediated gene expression triggered by synaptic activity. Nat Neurosci 2001, 4:261-267.

22. Hardingham GE, Chawla S, Johnson CM, Bading $\mathrm{H}$ : Distinct functions of nuclear and cytoplasmic calcium in the control of gene expression. Nature 1997, 385:260-265.

23. Mayr B, Montminy M: Transcriptional regulation by the phosphorylationdependent factor CREB. Nat Rev Mol Cell Biol 2001, 2:599-609.

24. Silva AJ, Kogan JH, Frankland PW, Kida S: CREB and memory. Annu Rev Neurosci 1998, 21:127-148.

25. Paşca SP, Portmann T, Voineagu I, Yazawa M, Shcheglovitov A, Pasca AM, Cord B, Palmer TD, Chikahisa S, Nishino S, Bernstein JA, Hallmayer J, Geschwind DH, Dolmetsch RE: Using iPSC-derived neurons to uncover cellular phenotypes associated with Timothy syndrome. Nat Med 2011, 17:1657-1662.

26. Krey JF, Pasca SP, Shcheglovitov A, Yazawa M, Schwemberger R, Rasmusson R, Dolmetsch RE: Timothy syndrome is associated with activity-dependent dendritic retraction in rodent and human neurons. Nat Neurosci 2013, 16:201-209.

27. Langfelder P, Horvath S: WGCNA: an R package for weighted correlation network analysis. BMC Bioinformatics 2008, 9:559.

28. Zhang B, Horvath S: A general framework for weighted gene coexpression network analysis. Stat Appl Genet Mol Biol 2005, 4:1544-6115.

29. Carter ME, Brunet A: FOXO transcription factors. Curr Biol 2007, 17:R113-R114.

30. Salih DA, Rashid AJ, Colas D, de la Torre-Ubieta L, Zhu RP, Morgan AA, Santo EE, Ucar D, Devarajan K, Cole CJ, Madison DV, Shamloo M, Butte AJ, Bonni A, Josselyn SA, Brunet A: FoxO6 regulates memory consolidation and synaptic function. Genes Dev 2012, 26:2780-2801.

31. Ozcan L, Wong CC, Li G, XU T, Pajvani U, Park SK, Wronska A, Chen BX, Marks AR, Fukamizu A, Backs J, Singer HA, Yates JR, Accili D, Tabas I: Calcium signaling through CaMKII regulates hepatic glucose production in fasting and obesity. Cell Metab 2012, 15:739-751.

32. Dick $\mathrm{O}$, Bading $\mathrm{H}$ : Synaptic activity and nuclear calcium signaling protect hippocampal neurons from death signal-associated nuclear translocation of FoxO3a induced by extrasynaptic N-methyl-D-aspartate receptors. J Biol Chem 2010, 285:19354-19361.

33. Voineagu I, Wang X, Johnston P, Lowe JK, Tian Y, Horvath S, Mill J, Cantor RM, Blencowe BJ, Geschwind DH: Transcriptomic analysis of autistic brain reveals convergent molecular pathology. Nature 2011, 474:380-384

34. Parikshak NN, Luo R, Zhang A, Won H, Lowe JK, Chandran V, Horvath S, Geschwind DH: Integrative functional genomic analyses implicate specific molecular pathways and circuits in autism. Cell 2013, 155:1008-1021.

35. Konopka G, Wexler E, Rosen E, Mukamel Z, Osborn GE, Chen L, Lu D, Gao F, Gao K, Lowe JK, Geschwind DH: Modeling the functional genomics of autism using human neurons. Mol Psychiatry 2012, 17:202-214

36. Allen JD, Xie Y, Chen M, Girard L, Xiao G: Comparing statistical methods for constructing large scale gene networks. PLoS One 2012, 7:e29348

37. Horvath S, Dong J: Geometric interpretation of gene coexpression network analysis. PLoS Comput Biol 2008, 4:e1000117.

38. Benjamini $Y$, Hochberg $Y$ : Controlling the false discovery rate - a practical and powerful approach to multiple testing. J Roy Stat Soc B Met 1995, 57:289-300.

39. Csardi G, Nepusz T: The igraph software package for complex network research. Inter J Complex Syst 2006, 1695: [http://igraph.org]

40. Langfelder $\mathrm{P}$, Luo R, Oldham MC, Horvath S: Is my network module preserved and reproducible? PLoS Comput Biol 2011, 7:e1001057.

41. Stein $J$, de la Torre-Ubieta $L$, Tian $Y$, Parikshak NN, Hernandez IA, Marchetto MC, Baker DK, Lu D, Hinman CR, Lowe JK, Wexler EM, Muotri AR, Gage FH, Kosik KS, Geschwind DH: A quantitative framework to evaluate modeling of cortical development by neural stem cells. Neuron 2014, 83:69-86.

42. Kang HJ, Kawasawa Yl, Cheng F, Zhu Y, Xu X, Li M, Sousa AM, Pletikos M, Meyer KA, Sedmak G, Guennel T, Shin Y, Johnson MB, Krsnik Z, Mayer S, Fertuzinhos S, Umlauf S, Lisgo SN, Vortmeyer A, Weinberger DR, Mane S, Hyde TM, Huttner A, Reimers M, Kleinman JE, Sestan N: Spatio-temporal transcriptome of the human brain. Nature 2011, 478:483-489.

43. Smyth GK: Limma: linear models for microarray data. In Bioinformatics and Computational Biology Solutions Using R and Bioconductor. New York: Springer; 2005:397-420

44. Zambon AC, Gaj S, Ho I, Hanspers K, Vranizan K, Evelo CT, Conklin BR, Pico AR, Salomonis N: GO-Elite: a flexible solution for pathway and ontology over-representation. Bioinformatics 2012, 28:2209-2210.

45. Mckee AE, Neretti N, Carvalho LE, Meyer CA, Fox EA, Brodsky AS, Silver PA: Exon expression profiling reveals stimulus-mediated exon use in neural cells. Genome Biol 2007, 8:R159.

46. Kim TK, Hemberg M, Gray JM, Costa AM, Bear DM, Wu J, Harmin DA Laptewicz M, Barbara-Haley K, Kuersten S, Markenscoff-Papadimitriou E, Kuhl D, Bito H, Worley PF, Kreiman G, Greenberg ME: Widespread transcription at neuronal activity-regulated enhancers. Nature 2010, 465:182-U165.

47. Basu SN, Kollu R, Banerjee-Basu S: AutDB: a gene reference resource for autism research. Nucleic Acids Res 2009, 37:D832-D836.

48. Lubs HA, Stevenson RE, Schwartz CE: Fragile $X$ and X-linked intellectual disability: four decades of discovery. Am J Hum Genet 2012, 90:579-590.

49. Inlow JK, Restifo LL: Molecular and comparative genetics of mental retardation. Genetics 2004, 166:835-881.

50. Ropers HH: Genetics of intellectual disability. Curr Opin Genet Dev 2008, 18:241-250.

51. van Bokhoven $\mathrm{H}$ : Genetic and epigenetic networks in intellectual disabilities. Annu Rev Genet 2011, 45:81-104.

52. Frith MC, Fu Y, Yu L, Chen JF, Hansen U, Weng Z: Detection of functional DNA motifs via statistical over-representation. Nucleic Acids Res 2004, 32:1372-1381.

53. Matys V, Fricke E, Geffers R, Gossling E, Haubrock M, Hehl R, Hornischer K, Karas D, Kel AE, Kel-Margoulis OV, Kloos DU, Land S, Lewicki-Potapov B, Michael H, Munch R, Reuter I, Rotert S, Saxel H, Scheer M, Thiele S, Wingender E: TRANSFAC: transcriptional regulation, from patterns to profiles. Nucleic Acids Res 2003, 31:374-378.

54. Matys V, Kel-Margoulis OV, Fricke E, Liebich I, Land S, Barre-Dirrie A, Reuter I, Chekmenev D, Krull M, Hornischer K, Voss N, Stegmaier P, Lewicki-Potapov B, Saxel $\mathrm{H}$, Kel AE, Wingender E: TRANSFAC and its module TRANSCompel: transcriptional gene regulation in eukaryotes. Nucleic Acids Res 2006, 34:D108-D110.

55. ENCODE Project Consortium: A user's guide to the encyclopedia of DNA elements (ENCODE). PLoS Bio/ 2011, 9:e1001046 [http://genome.ucsc.edu/ ENCODE/dataMatrix/encodeChipMatrixHuman.html] 
56. Dunham I, Kundaje A, Aldred SF, Collins PJ, Davis C, Doyle F, Epstein CB, Frietze S, Harrow J, Kaul R, Khatun J, Lajoie BR, Landt SG, Lee BK, Pauli F, Rosenbloom KR, Sabo P, Safi A, Sanyal A, Shoresh N, Simon JM, Song L, Trinklein ND, Altshuler RC, Birney E, Brown JB, Cheng C, Djebali S, Dong XJ, Dunham I, et al: An integrated encyclopedia of DNA elements in the human genome. Nature 2012, 489:57-74.

57. Lachmann A, Xu H, Krishnan J, Berger SI, Mazloom AR, Ma'ayan A: ChEA: transcription factor regulation inferred from integrating genome-wide ChIP-X experiments. Bioinformatics 2010, 26:2438-2444.

58. He XB, Yi SH, Rhee YH, Kim H, Han YM, Lee SH, Lee H, Park CH, Lee YS, Richardson E, Kim BW: Prolonged membrane depolarization enhances midbrain dopamine neuron differentiation via epigenetic histone modifications. Stem Cells 2011, 29:1861-1873.

59. Hua JY, Smear MC, Baier H, Smith SJ: Regulation of axon growth in vivo by activity-based competition. Nature 2005, 434:1022-1026.

60. Schor IE, Rascovan N, Pelisch F, Allo M, Kornblihtt AR: Neuronal cell depolarization induces intragenic chromatin modifications affecting NCAM alternative splicing. Proc Natl Acad Sci U S A 2009, 106:4325-4330.

61. Adams DS, Levin M: Endogenous voltage gradients as mediators of cellcell communication: strategies for investigating bioelectrical signals during pattern formation. Cell Tissue Res 2013, 352:95-122.

62. Spitzer NC: Electrical activity in early neuronal development. Nature 2006, 444:707-712.

63. Sundelacruz S, Levin M, Kaplan DL: Role of membrane potential in the regulation of cell proliferation and differentiation. Stem Cell Rev 2009, 5:231-246.

64. Nagamani SC, Zhang F, Shchelochkov OA, Bi W, Ou Z, Scaglia F, Probst FJ, Shinawi M, Eng C, Hunter JV, Sparagana S, Lagoe E, Fong CT, Pearson M Doco-Fenzy M, Landais E, Mozelle M, Chinault AC, Patel A, Bacino CA, Sahoo T, Kang SH, Cheung SW, Lupski JR, Stankiewicz P: Microdeletions including YWHAE in the Miller-Dieker syndrome region on chromosome 17p13.3 result in facial dysmorphisms, growth restriction, and cognitive impairment. J Med Genet 2009, 46:825-833.

65. Thevenon J, Callier P, Andrieux J, Delobel B, David A, Sukno S, Minot D, Mosca Anne L, Marle N, Sanlaville D: 12p13.33 microdeletion including ELKS/ERC1, a new locus associated with childhood apraxia of speech. Eur J Hum Genet 2013, 21:82-88.

66. Aleksic B, Kushima I, Hashimoto R, Ohi K, Ikeda M, Yoshimi A, Nakamura Y, Ito $Y$, Okochi T, Fukuo $Y$, Yasuda $Y$, Fukumoto M, Yamamori $\mathrm{H}$, Ujike $\mathrm{H}_{\text {, }}$ Suzuki M, Inada T, Takeda M, Kaibuchi K, Iwata N, Ozaki N: Analysis of the VAV3 as candidate gene for schizophrenia: evidences from voxel-based morphometry and mutation screening. Schizophr Bull 2013, 39:720-728.

67. Lehman NL: The ubiquitin proteasome system in neuropathology. Acta Neuropathol 2009, 118:329-347.

68. Bayes A, van de Lagemaat LN, Collins MO, Croning MD, Whittle IR, Choudhary JS, Grant SG: Characterization of the proteome, diseases and evolution of the human postsynaptic density. Nat Neurosci 2011, 14:19-21.

69. Liao P, Soong TW: CaV1.2 channelopathies: from arrhythmias to autism, bipolar disorder, and immunodeficiency. Pflugers Arch 2010, 460:353-359.

70. Artigas-Pallares J, Gabau-Vila E, Guitart-Feliubadalo M: Syndromic autism: II. Genetic syndromes associated with autism. Rev Neurol 2005, 40:S151-S162.

71. Holroyd S, Reiss AL, Bryan RN: Autistic features in Joubert syndrome: a genetic disorder with agenesis of the cerebellar vermis. Biol Psychiatry 1991, 29:287-294.

72. Kumandas S, Akcakus M, Coskun A, Gumus H: Joubert syndrome: review and report of seven new cases. Eur J Neurol 2004, 11:505-510.

73. Ozonoff S, Williams BJ, Gale S, Miller JN: Autism and autistic behavior in Joubert syndrome. J Child Neurol 1999, 14:636-641.

74. Geschwind DH: Autism: many genes, common pathways? Cell 2008, 135:391-395.

75. Greer PL, Greenberg ME: From synapse to nucleus: calcium-dependent gene transcription in the control of synapse development and function. Neuron 2008, 59:846-860.

76. de la Torre-Ubieta L, Bonni A: Transcriptional regulation of neuronal polarity and morphogenesis in the mammalian brain. Neuron 2011, 72:22-40.

77. Macian F: NFAT proteins: key regulators of T-cell development and function. Nat Rev Immunol 2005, 5:472-484.

78. Muller MR, Rao A: NFAT, immunity and cancer: a transcription factor comes of age. Nat Rev Immunol 2010, 10:645-656.

79. Lonze BE, Ginty DD: Function and regulation of CREB family transcription factors in the nervous system. Neuron 2002, 35:605-623.
80. Zhu X, Need AC, Petrovski S, Goldstein DB: One gene, many neuropsychiatric disorders: lessons from Mendelian diseases. Nat Neurosci 2014, 17:773-781.

81. Flavell SW, Cowan CW, Kim TK, Greer PL, Lin Y, Paradis S, Griffith EC, Hu LS, Chen C, Greenberg ME: Activity-dependent regulation of MEF2 transcription factors suppresses excitatory synapse number. Science 2006, 311:1008-1012.

82. Dugani CB, Paquin A, Kaplan DR, Miller FD: Coffin-Lowry syndrome: A role for RSK2 in mammalian neurogenesis. Dev Biol 2010, 347:348-359.

83. Frodin M, Gammeltoft S: Role and regulation of $90 \mathrm{kDa}$ ribosomal S6 kinase (RSK) in signal transduction. Mol Cell Endocrinol 1999, 151:65-77.

84. Anjum R, Blenis J: The RSK family of kinases: emerging roles in cellular signalling. Nat Rev Mol Cell Biol 2008, 9:747-758.

85. DU KY, Montminy M: CREB is a regulatory target for the protein kinase Akt/PKB. J Biol Chem 1998, 273:32377-32379.

86. Kay JC, Xia CM, Liu M, Shen S, Yu SJ, Chung C, Qiao LY: Endogenous PI3K/ Akt and NMDAR act independently in the regulation of CREB activity in lumbosacral spinal cord in cystitis. Exp Neurol 2013, 250:366-375.

87. Rossin EJ, Lage K, Raychaudhuri S, Xavier RJ, Tatar D, Benita Y, Cotsapas C, Daly MJ: Proteins encoded in genomic regions associated with immune-mediated disease physically interact and suggest underlying biology. PLoS Genet 2011, 7:e1001273.

doi:10.1186/s13073-014-0075-5

Cite this article as: Tian et al: Alteration in basal and depolarization induced transcriptional network in iPSC derived neurons from Timothy syndrome. Genome Medicine 2014 6:75.

\section{Submit your next manuscript to BioMed Central and take full advantage of:}

- Convenient online submission

- Thorough peer review

- No space constraints or color figure charges

- Immediate publication on acceptance

- Inclusion in PubMed, CAS, Scopus and Google Scholar

- Research which is freely available for redistribution 